\title{
Optimization of Parametric Effect of Ultrasonic Welding
}

\section{S. Sreekanth ${ }^{1}$, P Sreenivasulu ${ }^{1}$, C. Mohan Naidu ${ }^{2}$}

${ }^{1}$ M. Tech Scholar, Department of Mechanical Engineering, SKD Engineering College, Gooty, Andhra Pradesh, India

${ }^{2}$ Associate Professor, HOD, Department of Mechanical Engineering, SKD Engineering College, Gooty, Andhra Pradesh, India

\begin{abstract}
In today's world, aluminium and its alloy is showing promising characteristics for replacing other materials due its excellent properties like light weight, corrosion resistance, high strength and toughness. Conventional welding for these materials creates some challenges like porosity, hot cracking and void formation. Ultrasonic welding gives some ultimate solution to these problems as the material experience only $30 \%$ of its melting point temperature. Ultrasonic welding is a creative system for joining metals and composites rapidly and safely owing to a highfrequency vibration consolidated with pressure. The process has a widespread application in electrical, automotive, aerospace, medical and packaging industry. In the present research work, a numerical model is proposed for the evaluation of heat generation due to deformation and friction during welding. The developed model is equipped for predicting the interface temperature and stress distribution during ultrasonic welding and their impacts on sonotrode, anvil and welded parts. The effect of tool (sonotrode) shape also studied. Response surface methodology (RSM) with Box-Behnken design has been implemented to design the experimental setup and establish a co-relation between process parameters viz. pressure, amplitude and welding time with the output response as tensile strength. RSM is coupled with desirability function is utilized to optimize the parameters for a desired tensile strength of the joint. The result of numerical model is compared with the experimental value and found to be in good agreement.
\end{abstract}

Keywords : Ultrasonic Welding, FEM, RSM, Desirability Function, Thermocouple

\section{INTRODUCTION}

Ultrasound is the oscillating sound wave having a frequency more than $16 \mathrm{KHz}$ which is well above the human hearing. It can be used for welding of wide range of materials with a frequency more than 20 $\mathrm{KHz}$ with vibrational amplitude of more than $10 \mu \mathrm{m}$ resulting with an ultrasonic energy. Substantial increasing in quality and performance improvements is achieved by using ultrasonic energy in machining technological.

\section{FUNDAMENTAL PRINCIPLE}

Ultrasonic metal welding is a solid state joining process used to weld thin metal sheets, foils and wire.
The principle of this welding operation follows from creation of an oscillating shear force (ultrasonic vibrations) under moderate pressure (normal force) at the interface between the mating surfaces, to separate liquids contaminants, voids, oxide layer and offer new contact at many points.

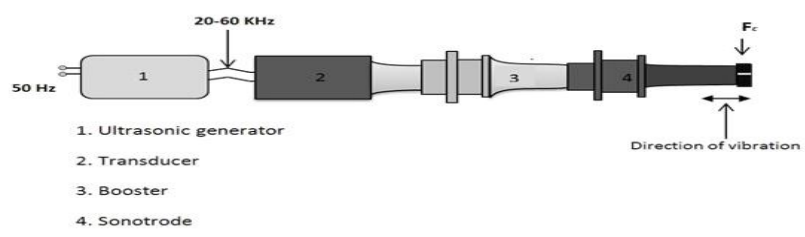

Fig 1. Principle of ultrasonic welding The vibrations are applied parallel to the weld contact area. As shown in figure a supply of $50 \mathrm{~Hz}$ electrical energy is supplied to the ultrasonic 
generator which amplifies it up to $20 \mathrm{KHz}-60 \mathrm{KHz}$ electrical energy and the same provided to the piezoelectric transducer which converts electrical energy into mechanical vibrations which is then enhanced by booster and transferred up to the sonotrode. When the vibrations reached to the contact area and results in oscillation causing an increase in diffusion across the weld interface and produces weld similar to that of diffusion welding.

\section{WEDGE-REED SYSTEM}

In the wedge-reed system demonstrated in Figure (a), the components are the generator, transducer, and wedge and reed arrangement of segments, used to deliver the ultrasonic vibrational energy and provide it to the work piece that are clamped between the sonotrode tip and anvil. A pneumatic, pressure driven or electrical gadget can be utilized for applying the normal force by controlling the upwards and downwards motion of the sonotrode. Typically, the amplitude which is in the range of 10 to $100 \mu \mathrm{m}$ can be varying as per the tool design. The purpose of the wedge is to enhance the amplitude and that is transfer by the reed to the sonotrode tip.

\section{LATERAL DRIVE SYSTEM}

This type of ultrasonic welding system is more commonly used, as shown in Figure (b) the system comprises of a generator, transducer, booster and sonotrode. Sometimes, the combination of sonotrode and booster which is then connected to the transducer is termed as welding stack. In a same way to the wedge-reed framework, the transducer creates a vibration of the piezoelectric plates. The booster expands the vibrational amplitude relying upon the input and serves as a mounting for the welding stack. The sonotrode can further expand the amplitude up to the welding range. In this system, the sonotrode is attached parallel to the direction of vibration of the tool. Hence, the vibration energy is transmitted to the workpiece in a transverse way. The parts, generally sheets or foils were clamped between moving sonotrode and stationary anvil in lap configuration. The ultrasonic vibration of the sonotrode is in the parallel direction to the part surface, generating a scrubbing movement at mating surfaces. The action creates heat due to friction caused by the relative movement in the mating parts, as a result of which shear deformation occurs at the zone with subsequent weld formation.
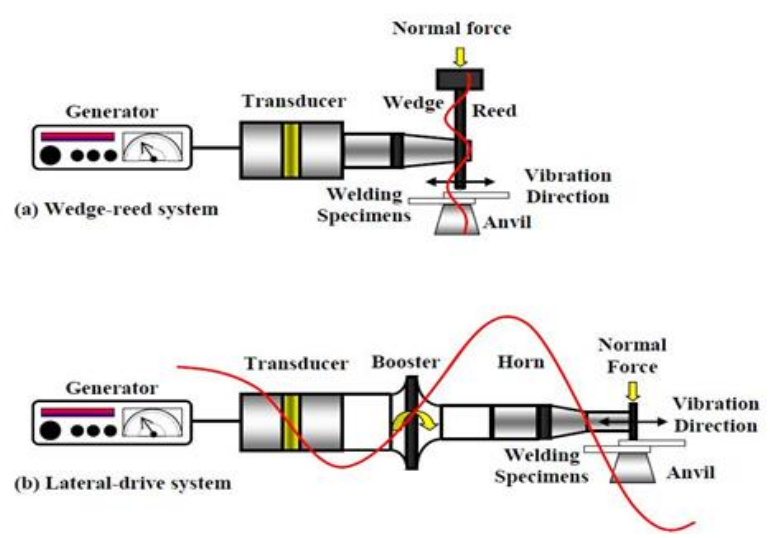

Fig 2. Types of ultrasonic metal welding system, (a) Wedge reed system, (b) Lateral drive system.

\section{SUMMARY}

The above chapter highlights the necessity of Ultrasonic welding in the area of manufacturing. The chapter also gives a brief idea about different types of ultrasonic welding and their uses.

\section{MECHANICS OF ULTRASONIC WELDING SHEAR FORCES ACTING AT THE SONOTRODE TIP}

The chapter will be discussing the mechanics of the ultrasonic metal welding. A numerical analysis has been done for the applied loads and deformation of the workpiece, sonotrode and anvil under the same load. The figure 3.1 shows in more details about the process, where the only external force applied is the clamping force applied at the top of the sonotrode used the kept the materials in contact. As a result of 
the applied clamping force, the knurl pattern made on the sonotrode were inserted into the top part and helps the system to transfer vibration into the weld interface in synchronize with sonotrode. From the figure, it is shown that the not only the normal force $F_{N}$ but also the net shear force $F_{I}$ is also applied at weld interface as a result of the transverse vibration of the sonotrode.

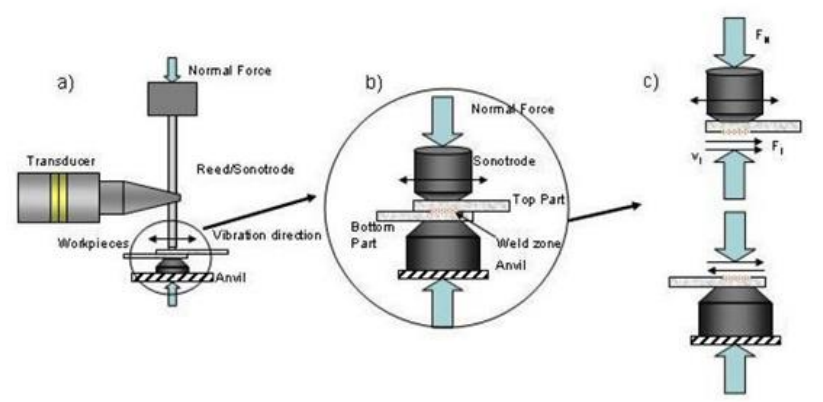

Fig 2. Force morphology of the Wedge Reed System

The model developed in the study is for a spherical sonotrode where the compressive stresses were not uniform and is time dependent. The study can also be applied for other shaped sonotrodes. To calculate the Shear force at weld interface we first needs to concentrate on the few factors like the component of the normal force $\mathrm{F}_{\mathrm{N}}$, heating of the workpiece and sonotrode tip during welding, and the impact of the part geometry on welding. The heating caused during welding were calculated from heat flux equations at the deforming area of weld interface and the frictional area where the parts are in contact.

However, these complex stresses will be extinct within a small distance leading to a uniform stress distribution throughout the cross section but during welding the portion subject to a shear stress. Hence, a combined compressive and shearing model is assumed for the plastic deformation of the material. To analyze this combined stress Tresca's yield criteria is used as stated below:

$F s \leq \sqrt{\left(\left(\frac{Y(T)}{2}\right)^{2}-\left(\frac{F_{N}}{2 A_{s}}\right)^{2}\right) \times A_{s}}=\tau_{y} \times A_{s}$
Where:

$F_{s}=$ Shear force at the sonotrode tip.

$\mathrm{Y}(\mathrm{T})=$ Temperature dependent yield strength

$\mathrm{A}_{\mathrm{s}}=$ Sonotrode area in contact with the top part

$\mathrm{F}_{\mathrm{N}}=$ Normal force on the sonotrode

From the condition if $F S$ is less than R.H.S then top part will vibrate with the sonotrode simultaneously, but if it's equal then tip sticking will occur.

\section{CONTACT STRESSES AT INTERFACE}

Contact stress is nothing but the compressive stresses generated by the sonotrode which is effectively distributed over the larger area of the top part. The magnitude of the contact stress depends upon the thickness of the top part as it spreads out with larger area. In case of a spherical sonotrode shape, the contact stress is maximum towards the center.

\section{SHEAR FORCES AT WELD INTERFACE}

For calculating the forces at the interface one first needs to consider the dynamics of the part geometry, as we know that at the mating part a combined shearnormal force is applied, so let us first assume both the bottom and top part are rigid and length is reduced up to the sonotrode contact area. The bottom part is fixed with the anvil while the top part moves with the sonotrode. This will allow the dynamics of the part considered single body motion, without any chances of resonance occurs for the case of the larger body. During welding, a thin area of plastic deformation is resulted with intense shearing and bonding occurs between the parts. It is considered that the top part vibrates in same amplitude with the sonotrode and same can be simply expressed as:

$$
\xi(t)=\xi_{0} \sin (f t)
$$

Where:

$f=$ frequency of vibration

$\xi_{0}=$ sonotrode amplitude 
As top part oscillates with the sonotrode, so their acceleration is same and can be expressed as:

$$
\frac{\partial^{2} \xi}{\partial t^{2}}=-f^{2} \xi_{0} \sin (f t)
$$

With the increase in deflection of the top part the sonotrode forces are also increases, hence maximum acceleration has to be considered.

$$
\begin{aligned}
& m \times \xi_{\max }=F S-F_{I} \\
& A s \times d \times \rho \times f^{2} \times \xi_{0}=F S-F_{I}
\end{aligned}
$$

Where:

$\rho=$ density of the material

$\mathrm{m}=$ mass of the top part

As it said earlier that the anvil is fixed and so as the bottom part is fixed to the anvil, so anvil force $F_{A}$ is equal to the interface force $F_{\text {. }}$. Now let us consider for an extended length of the part, which in a direction parallel to the vibration and the force developed is in one direction. The force for extension $F_{E X}$ has its maximum when the deflection is maximum at the end.

$$
m \times \xi_{\max }=F_{S}-F_{I}-F_{E X}
$$

As top part moves with the sonotrode, so the extension of the top part is also excited by sonotrode frequency and velocity. So the force of extension as a function of part length can be expressed as follows:

$$
F_{E X}=E \times A \times \frac{f}{c} \times \xi_{0} \times \tan \left(\frac{f}{c} \times l\right)
$$

Where:

$\mathrm{E}=$ young's modulus

$A=$ area perpendicular to the vibration

$\mathrm{c}=$ wave velocity (longitudinal)

$1=$ extension length

By solving the Eq 3.5 for calculating shear force Fs s compare with Eq 3.1 which says the parts has a plastic limit although it is considered to be rigid.

$$
m \times \xi_{\max }+F_{E X}+F_{I} \leq \sqrt{\left(\left(\frac{Y(T)}{2}\right)^{2}-\left(\frac{F_{N}}{2 A_{s}}\right)^{2}\right) \times A_{s}}
$$

Now for the interface forces

$$
F_{I}=\sqrt{\left(\left(\frac{Y(T)}{2}\right)^{2}-\left(\frac{F_{X}}{2 A_{s}}\right)^{2}\right) \times A_{s}}-m \times \xi_{\max }-F_{E X}
$$

From the R.H.S of the expression which has three parts with the first part depends upon temperature and normal force, while the second is constant for a given material and geometry. Now FEx will became very high for top part extension in anti-resonance case in return it will make interface force $F_{I}$ very small by making the weld impossible. It is essential to have some amount of interface force for the welding to be accomplished.

\section{FORCES AT WELD INTERFACE}

The interface forces are hugely depends upon the process of welding, so let us first discuss the welding process in brief:

Before welding the parts when comes in contact surface impurities present on surface which restricts the bonglyjng to take place with the application of static normal force, which is not sufficient for the net plastic deformation required in zone. When the ultrasonic vibration starts the surface asperities comes in contact and undergoes a shear deformation. The process generates an adequate amount of localize heat resulting in softening of material and at the end of the total cycle the deformation spreads upto the entire area allowing metal to metal joining.

The interface area consists of three parts:

1. Aw is the weld area, where the whole plastic deformation of the material takes place and joint is formed. It can also termed as deformation zone area Adz.

2. Afr is the frictional area situated adjacent to Aw, here no welding occurs but plastic deformation takes place. 
3. Anc non-contact area, where the surface are not in contact.

At the deformation zone area the limit for the contact stresses will be given as:

$$
\frac{F_{N}}{A_{D Z}} \leq \frac{F_{N}}{A_{W}+A_{F R}}<<\frac{F_{N}}{\lim \stackrel{A_{N C}}{\longrightarrow} A_{D Z}}
$$

From the Eq 3.9,

$\frac{F_{N}}{A_{D Z}}=\sigma_{\mathrm{S}}$

is the contact stress or normal stress applied at the weld zone. A differential element is assumed from the weld interface for the calculation of welding force $\mathrm{F}_{\mathrm{w}}$, now of critical yield shear stress can be calculated as:

$$
\tau_{Y}(T)=\frac{d F_{W}}{d A}=\sqrt{\left(\frac{Y(T)}{2}\right)^{2}-\left(\frac{F_{N}}{2 A_{D Z}}\right)^{2}}
$$

From the above $\mathrm{Eq}$ it has been seen that stress depends upon temperature, by integrating welding force can be calculated

$$
F_{W}=\int_{A_{\pi}(t)} \sqrt{\left(\frac{Y(T)}{2}\right)^{2}-\left(\frac{F_{N}}{2 A_{D Z}}\right)^{2}} d A
$$

With integrating time dependent weld area, as the normal stress depends upon the temperature and normal force we can calculate the welding force depending upon time, temperature and normal force:

$$
F_{W}\left(T, t, F_{N}\right)=\int_{A_{\pi}(t)} \sqrt{\left(\frac{Y(T)}{2}\right)^{2}-\left(\frac{F_{N}}{2 A_{D Z}}\right)^{2}} A_{W}(t)
$$

There are two types of frictional forces arises in the welded area and its surroundings, one is the shear force responsible for welding and other is the friction force responsible for heating the circumference but does not actively involved in joining process.

As there is also a frictional force applied at welding area along with the welding force, so the interface force will be written as $F_{I}=F_{W}+F_{F R}$, but the frictional component of the force is difficult to calculate as it depends upon the vibration and coefficient if friction which increases with increase in weld area. Now the frictional force can be termed as:

$$
F F R=\mu s \times \sigma N \times A F R
$$

where:

$\mu_{s}=$ coefficient $\mathrm{f}$ static friction.

It's very difficult calculate the Eq 3.13 as neither the exact value $\sigma_{N}$ nor the frictional area were known. So the frictional force can also be written as:

$F_{F R}=\mu_{s} \times F_{N}$ (3.14) When the thickness of the material increases frictional area expands along with contact stresses. As the top size reduces with both the parts considered to be rigid and surfaces in contact were undergo plastic deformation during yield conditions arrive. The expression for the compressive stress can be deliberate by the ratio of normal force to the sonotrode area/deformation zone area. The extensions of both the parts were assumed to be elastic rods. The forces acting on the surfaces are equal and opposite in direction because the bottom part along with anvil was fixed. Hence, the top part equation of motion can be written as:

$m \quad x \xi_{\max }=F_{S}-F_{W}-F_{F R}-F_{E X}$

By substituting the value of $\mathrm{Fs}$ in $\mathrm{Eq} 3.1$ and by rearranging the Eq 3.15

$\left(m \times \zeta_{\max }\right)+F_{w}+F_{F R}+F_{E X} \leq \sqrt{\left(\left(\frac{Y(T)}{2}\right)^{2}-\left(\frac{F_{N}}{2 A_{s}}\right)^{2}\right) \times A_{s}}$

It is mandatory that the L.H.S of Eq 3.16 needs to be smaller than the R.H.S; otherwise sticking of the sonotrode will takes with the top part as a result of yielding.

\section{HEAT GENERATION DURING WELDING}

A substantial amount of heat is generated in the material parts, sonotrode and anvil due to plastic deformation at weld interface during ultrasonic metal welding. This generated heat with the change in temperature has a significant influence on material 
properties. The aim of this study is to generate a governing equation with the required assumption to give a good approximation for calculating the vibrational power dissipated at the weld interface.

During the initial period of welding, when the knurl pattern were engaged with top part plastic deformation also occur but very small in magnitude as compared to plastic deformation during welding so it is neglected. The heat generation is divided into two parts for the suitable evaluation of the model; one is the heat generation due to deformation of the material at the welding zone and the other is the heat generation due to friction which is confined to the surrounding of the welded zone.

\section{HEAT GENERATION AT THE WELD INTERFACE DUE TO DEFORMATION OF THE MATERIAL}

Initially plastic deformation will start in small patches and distributed randomly across the deformation zone. Similarly the power is also distributed in evenly in patches over the entire volume of the zone. If we consider the patches are equal in size and dissipates an equal amount of power, than the total power can be calculated by integrating: $\frac{P_{\text {total }}}{V_{D z}}=\frac{\int d P}{V_{D z}}$

For the calculation heat that is developed in deformation patches. Its needs go for a thin layer of shear elements at the plastic deformation zone. The shear element which is elastic in property with the work done on strained volume is given by product of shear angle and shear stress. This can assumed to be highest stress for the case of perfectly plastic material with no work hardening. Hence, the work done on the deformed volume can be written as:
The work done on the deformation volume is for a particular period of time is equal to the change in angle during the same amount of time, which can be explained by the ratio of top part deflection to the thickness of the deformed layer.

$\frac{\Delta d W}{\Delta t} \times \frac{1}{d V}=\tau_{y} \times \frac{\Delta \xi}{\Delta t \times d y}$

As we know that the rate of change of work done is the power, similarly the rate of change of amplitude is the average acoustic speed for amplitude of $\xi_{0}$ and frequency of $\mathrm{f}_{\mathrm{w}}$ id given by:

$\frac{\Delta W}{\Delta t}=P$
$\frac{\Delta \xi}{\Delta t}=v_{\text {arg }}=\frac{1}{T} \int_{0}^{T}\left|f \times \xi_{0} \cos (f t)\right|=4 \times \xi_{0} \times f_{w}$

Where:

$\mathrm{f}=$ frequency Vibration

$\mathrm{T}=$ time period of vibration

By substituting the Eq 3.20 in Eq 3.19 and solving, we can get the expression for power dissipated:

$$
\frac{d P}{d V}=\tau_{y} \times \frac{v_{a v g}}{d y}
$$

As the deformed element thickness is constant, so the differential volume $\mathrm{dV}$ can be substituted by $\mathrm{dA} \times \mathrm{dy}$ with multiplying both side by dy one can get:

$$
\frac{d P}{d A}=\tau_{y} \times v_{\text {avg }}
$$

or

$d P=\tau_{y} \times v_{\text {avg }} \times d A$

Now, by substituting the value of average differential power from Eq 3.22 in Eq 3.17:

$$
\frac{P_{\text {total }}}{d A}=\frac{\int d A \times \tau_{y} \times v_{\text {avg }}}{V_{D Z}}
$$

$\frac{d W}{d V}=\tau_{y} \times \gamma$

where:

$\gamma=$ angle of deformation 
Similarly for the Eq 3.10 the integration would be applied for weld area $A_{w}$ time and by replacing $V_{D Z}$ by $A_{D Z} \times d y$ and multiplying both side by $d y$ :

$$
\frac{P_{\text {total }}}{A_{D Z}}=\frac{\tau_{y} \times A_{w}(t) \times v_{\text {avg }}}{A_{D Z}}=\frac{F_{w}(t) \times v_{\text {avg }}}{A_{D Z}}
$$

Now the expression 3.24 gives the amount of vibrational power which generated due to plastic deformation in the welding zone area. As we know that the heat flux is the power dissipated over unit area, so the Eq 3.24 can be rewritten by putting the value of weld force from Eq 3.12 and also the average speed from Eq 3.20, the expression for the heat flux in the deformation zone area can be written as:

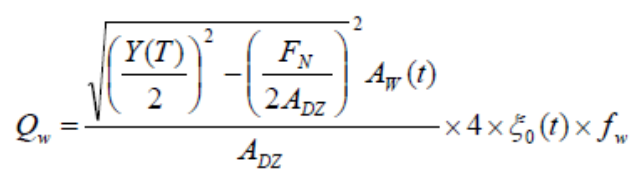

From the expression, the time dependence of the amplitude is only for the initial period of the weld cycle, during this period the amplitude of the sonotrode is not equal to amplitude at the weld interface.

\section{HEAT GENERATION IN THE WELD INTERFACE DUE TO FRICTION}

Heat generation in the surrounding of the welded zone can be calculated by the ratio of power dissipated per unit frictional area. The power dissipated can simply expressed by the product of average speed to the friction force:

$\frac{P_{P R}}{A_{R R}}=F_{F R} \times v_{a r g}$

Now, substituting the value average speed from Eq 3.20 and the value of friction force form Eq 3.14, one can get the expression for the heat flux due to friction as:

$$
Q_{F R}=\frac{\mu_{s} \times F_{N} \times 4 \times \xi_{0}(t) \times f_{w}}{A_{F R}}
$$

The heat flux due to friction is needs to be applied outside the weld area at the friction area, which is assumed to be twice the radius of weld area. The average interface speed is also changes by the shear deformation which is used in both the heat flux equations; the average speed needs to be considered as constant for most part of the weld cycle.

\section{FINITE ELEMENT MODELLING OF ULTRASONIC WELDING}

Finite element modeling (FEM) is a numerical method to find out the approximate solutions of the given problem. It divides the complex problems into simpler parts called finite elements. It helps in getting to obtain the appropriate solution for the define problem. There were various FEM based software in the present scenario such as ANSYS, SYSWELD, ABACUS, PROE, DEFORM, etc.

\section{MODELING THE TEMPERATURE DISTRIBUTION}

The temperature distribution modeling in weld interface, sonotrode, anvil is attempted in this study. A Two-dimensional rectangular Co-ordinate system was chosen due to complexity of the model. The different material properties (ASM Handbook volumes 1 and 2, 1998) considered in the present study for work piece, sonotrode, and anvil are presented in Table.1.

Table 1 Thermal and Physical properties for workpiece, sonotrode, and anvil

\begin{tabular}{lllll}
\hline Material & Thermal & Specific Density Young's Poisson' Co-eff. Of \\
conductivityheat & $(\rho)$ in & modulus s ratio & thermal \\
$(\mathrm{k})$ & in & & & $\begin{array}{l}\text { expansion } \\
\mathrm{W} / \mathrm{m}^{0} \mathrm{c}\end{array}$ \\
& $(\mathrm{C})$ in & $\mathrm{kg} / \mathrm{m}^{3}$ & $(\mathrm{E})$ in & in \\
& $\mathrm{J} / \mathrm{kg}^{0} \mathrm{c}$ & & $\mathrm{GPa}$ & $0 \mathrm{c}-1$ \\
\hline
\end{tabular}


Steel

(sonotrode, $\quad \begin{array}{llllll}24.3 & 460 & 7800 & 210 & 0.3 & 1.51 \times 10^{-5}\end{array}$

anvil)

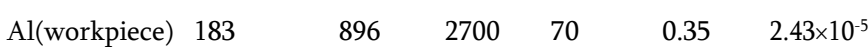

$Q_{w}=\sqrt{\left(\left(\frac{83.125 \times 10^{6}}{2}\right)^{2}-\left(\frac{1.8 \times 10^{5}}{2}\right)^{2}\right)} \times 4 \times 37 \times 10^{-6} \times 20000$

$=12.30 \times 10^{6} \mathrm{~W} / \mathrm{m}^{2}$

The expression for heat flux due to friction is derived in Eq 3.27, for a clamping force of $17.82 \mathrm{~N}$, coefficient of friction of 0.3 amplitude of $37 \mu \mathrm{m}$ corresponding to $80 \% \mathrm{~dB}$, by putting all these values:

$$
\begin{aligned}
& Q_{F R}=\frac{\mu \times F_{N} \times 4 \times \xi_{0} \times f_{w}}{A_{F R}} \\
& =\frac{0.3 \times 17.82 \times 4 \times 37 \times 10^{-6} \times 20000}{99 \times 10^{-6}}=2.82 \times 10^{6} \mathrm{~W} / \mathrm{m}^{2}
\end{aligned}
$$

The above calculate value of heat flux due friction is applied to the friction area which is two time the deformation zone area.

\section{SIMULATION OF FE MODEL}

Fig. 5 shows the dimension and boundary conditions for the for the developed axisymmetry model used for the analysis in ANSYS ${ }^{\circledR}$ APDL. It is shown in the figure that deformation area from origin upto $2.5 \mathrm{~mm}$ where the heat flux due to deformation is applied and from $2.5 \mathrm{~mm}$ to $5 \mathrm{~mm}$ heat flux due to friction is applied. The thickness of the sheet is chosen as 0.5 mm of commercial available Aluminum sheet, while sonotrode and anvil material is chosen as mild steel. The material properties for the required thermal analysis and structural analysis are listed in Table 4.1.

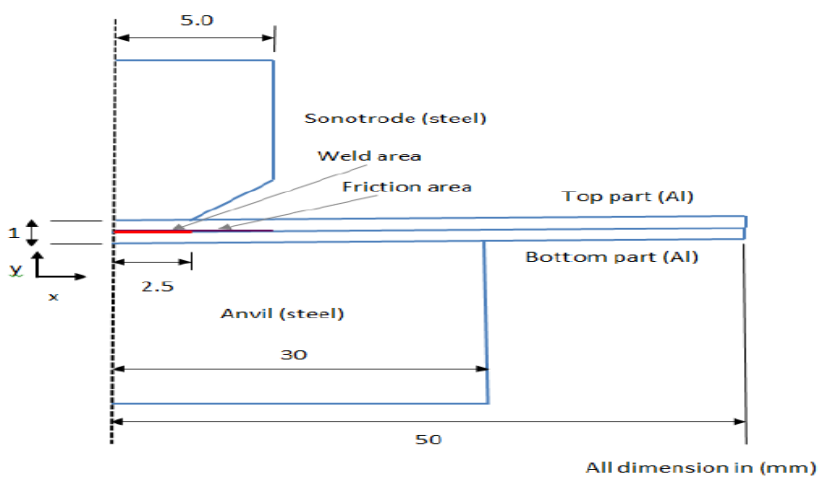

Fig 5. Axisymmetry model with boundary conditions 


\section{BOUNDARY CONDITIONS}

The initial condition for temperature $\mathrm{T}_{0}$ is assuming room temperature as $30^{\circ}$.

The heat loss due to convection to the surrounding is applied at the surface areas of the material parts which have not in contact with either sonotrode or anvil are listed below, as shown in Fig. 6. The convection heat coefficient is assumed as $5 \mathrm{~J} / \mathrm{m}^{0} \mathrm{C}$.

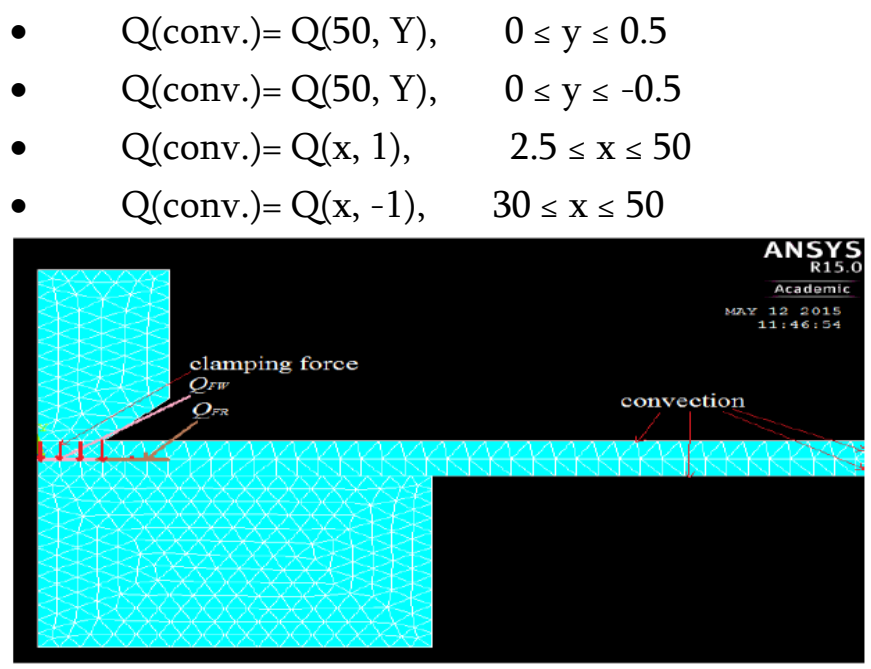

Fig 6. Elementary view of the FE model with applied loads.

\section{TRANSIENT THERMAL ANALYSIS}

The contact resistance of the faying surface is a component of burden, temperature and normal yield quality in contact materials. A triangular six-noded 2D structural solid element (plane 35) is chosen performing thermal analysis. The triangular shape makes it appropriate to model unpredictable mesh. Fig. 4.4 shows the shape, node position, and the coordinate system of the element. It has one degree of freedom, temperature change at every node. The 6-noded thermal element is pertinent to a 2-D transient or steady state thermal investigation. The mesh size picked was fine and contact is created between sonotrode with the top surface of workpiece, top workpiece with bottom workpiece, and bottom surface of workpiece with anvil.
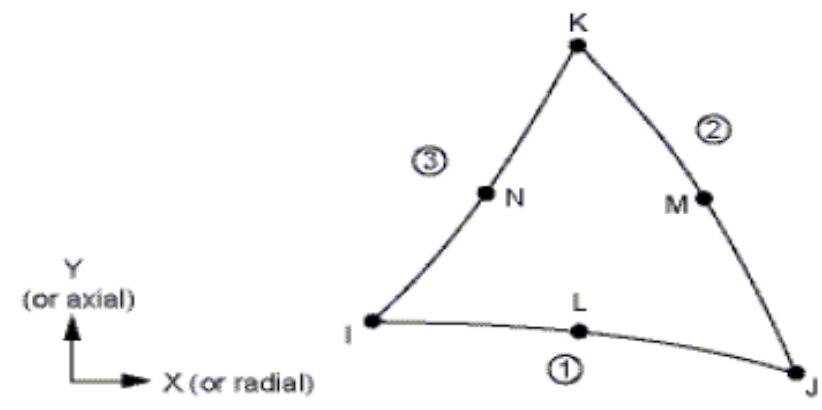

Fig 7. Shape and position of nodes for Plane 35 element

A surface to surface contact is established with the help of a 2-D three noded contact element (CONTA172) and 2-D target segment (TARGE169) was utilized to denote the respective contact surfaces. The simulation is first carried out for conical shape sonotrode and then extended to exponential shape and stepped shape.

As shown in Fig, the thermal loads like heat flux due to deformation were applied in weld area of $20 \mathrm{~mm}^{2}$ while the heat flux due to friction was applied in frictional area $60 \mathrm{~mm}^{2}$. The loss of heat due to convection was applied on the borders of the parts, which are not in contact with either sonotrode or anvil. For 2-D geometry, the areas are assumed to be lines. A full transient analysis was carried out for a time period of $0.5 \mathrm{sec}$ with time steps of $0.1 \mathrm{sec}$.

\section{TRANSIENT STRESS ANALYSIS}

The clamping force is applied on the nodes of the sonotrode as shown in Fig. 4.3, which are in contact with the top surface of the workpiece. The displacementt of the anvil is set as zero in all degrees of freedom. The element type is switched from thermal to structural for the Plane 35 element, and that is converted to a six-noded 2-D triangular structural solid (plane 2). The node location, shape and geometry of the plane are similar to the Fig. 4.4. 
Full transient analysis was chosen with time step size of 0.001 for a time period of $0.5 \mathrm{sec}$.

The simulation was repeated for three different shape of the sonotrode with constant material properties and dimension of the work piece and anvil. The results gathered from the structural and thermal analysis were presented in the subsequent section.

\section{RESULT AND DISCUSSION}

\section{TEMPERATURE DISTRIBUTION IN THE MODEL}

As discusseda earlier, the simulation was carried out for three different models having different shape of the sonotrode and the resultsware presented in this ssection. The maximum temperature reached for the conical shape is $169.238{ }^{\circ} \mathrm{C}$ at the end of weld time for a pressure of 1.8 bars. Fig. 4.5 shows the distribution of temperature for a conical shape sonotrode. It shows that the temperature reaches its maximum at the deformation zone and spreads more in the workpiece as compared to the sonotrode and anvil; this is because of the fact that the thermal conductivity of Aluminum is more as compared to mild Steel. The sonotrode and anvil experience a maximum temperature of $152.656{ }^{\circ} \mathrm{C}$.

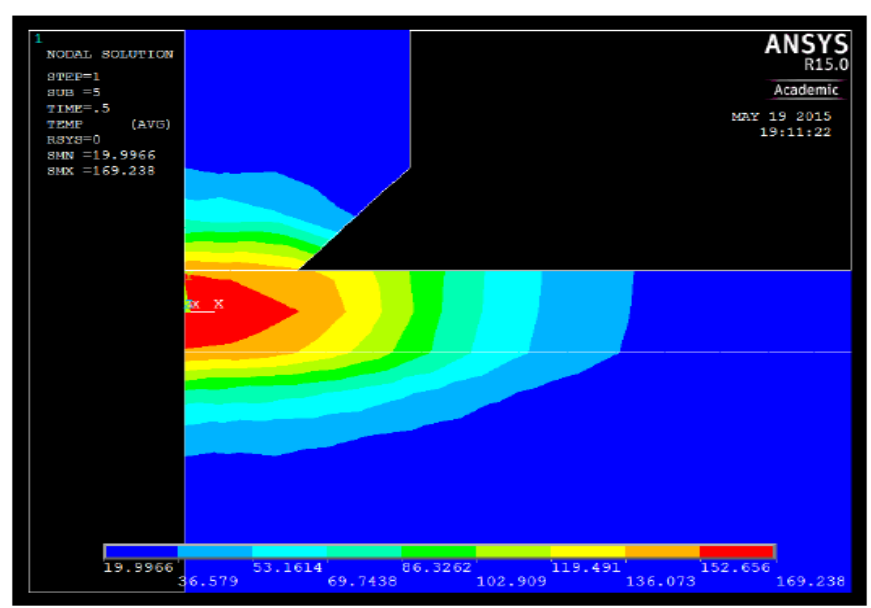

Fig 8. Temperature distribution in the model with conical shaped sonotrode
Fig. shows the distribution of temperature in an exponential shaped sonotrode with a maximum temperature of $171.439^{\circ} \mathrm{C}$ at the end of the weld time. The maximum temperature in the sonotrode and anvil have reached upto $154.612{ }^{\circ} \mathrm{C}$.

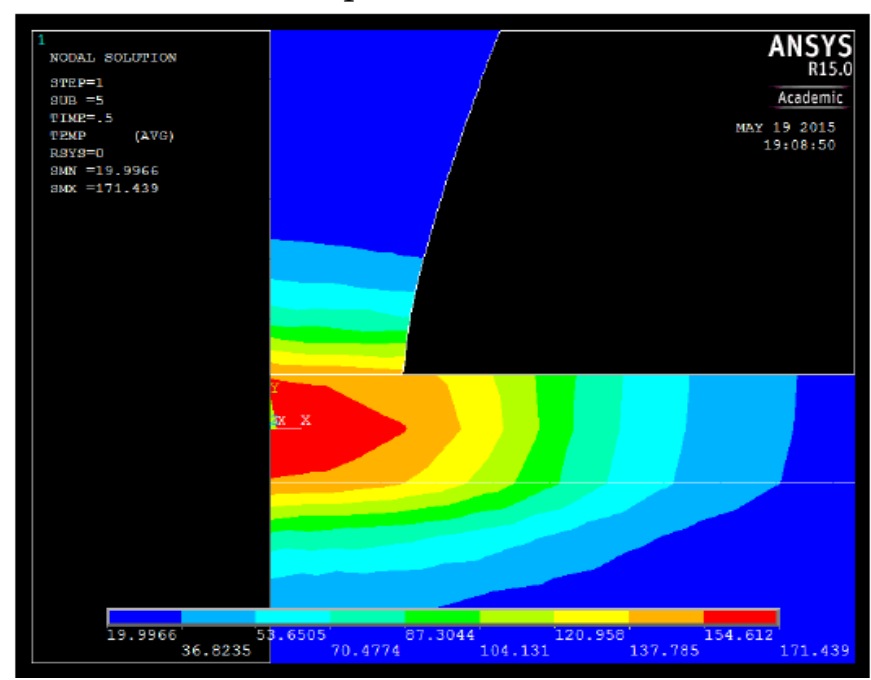

Fig 9. Temperature distribution in the model with exponential shaped sonotrode

Fig. shows the distribution of temperature in a stepped shaped sonotrode with a maximum temperature of $182.069^{\circ} \mathrm{C}$ at the end of the weld time. The maximum temperature in the sonotrode and anvil have reached upto $165.171^{\circ} \mathrm{C}$.

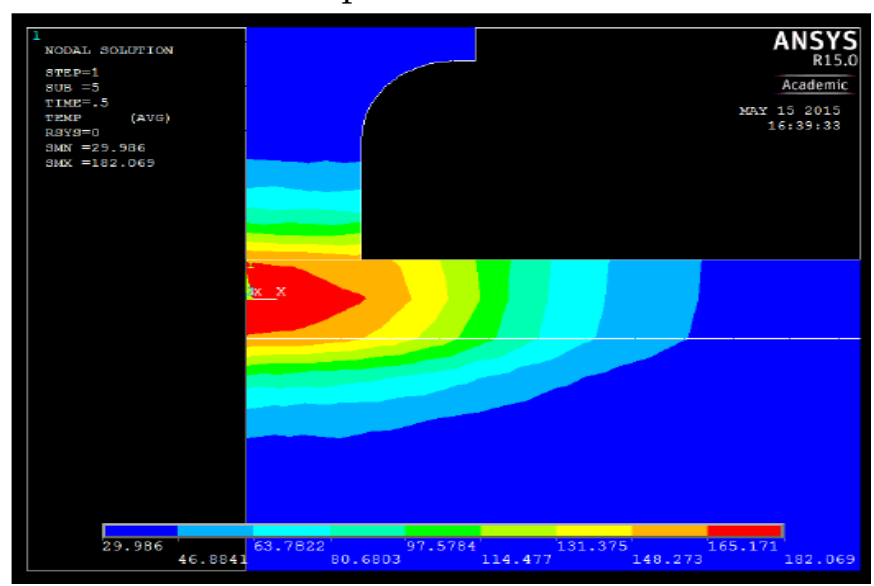

Fig 10. Temperature distribution in the model with stepped shaped sonotrode

Fig. shows the temperature variation with workpiece thickness. The variation ofttemperature from the center of the weld to the top or bottom surface of the workpiece is around $18.019{ }^{\circ} \mathrm{C}$ along the vertical 
direction. This observation can be used to forecast the area of heat affected zone in $\mathrm{Y}$ direction.

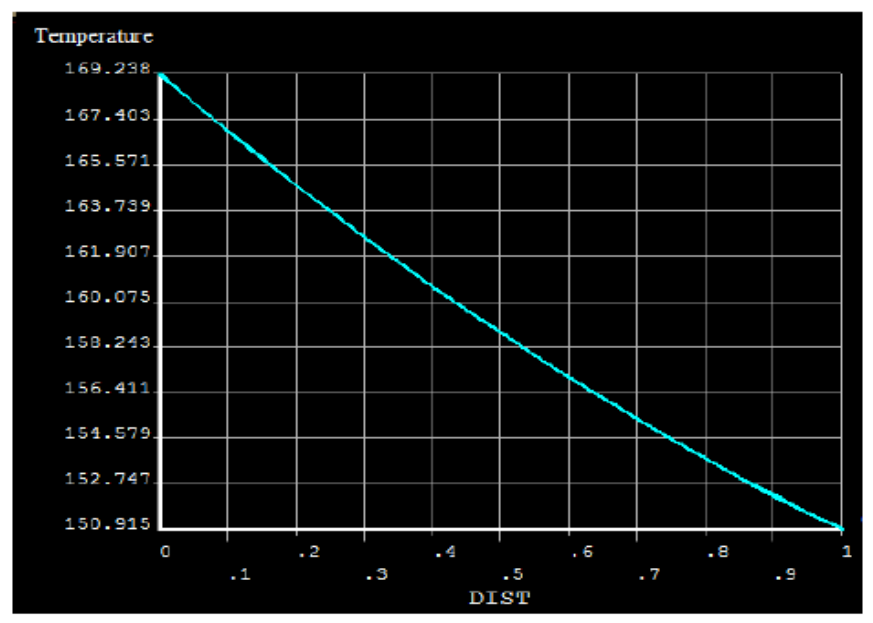

Fig 11. Temperature variation in the workpiece thickness

Fig. shows the change of temperature from origin to distance of $30 \mathrm{~mm}$ along X-direction. It can be seen that magnitude of temperature rapidly rises from a distance of $10 \mathrm{~mm}$ to the origin. The temperature in the figure is exactly from the weld interface. Fig. 4.10 shows the rise in temperature with each time step during welding in the weld interface. From the figure it can be summarized that the rise in temperature is directly proportional to the welddtime during welding.

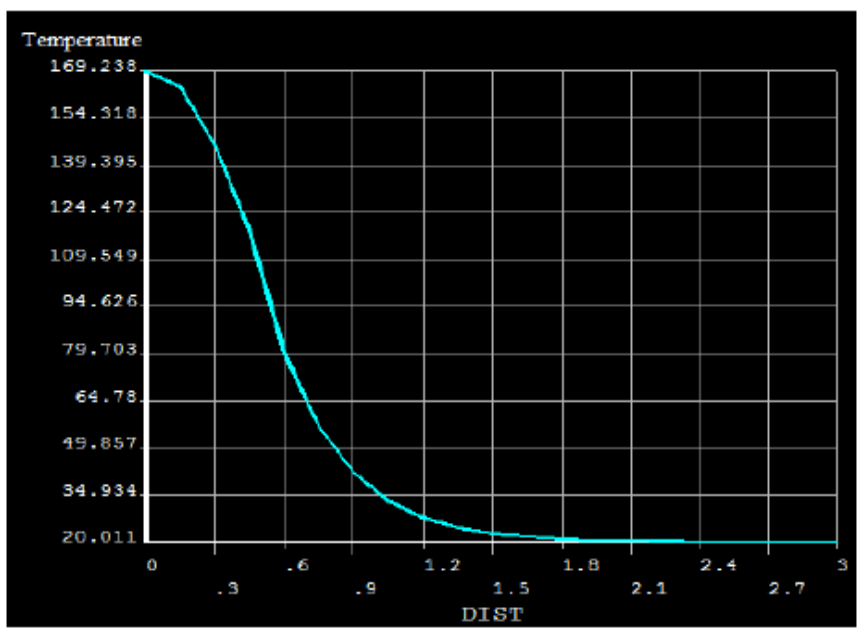

Fig 12. Temperature variation in weld interface along $\mathrm{X}$-direction

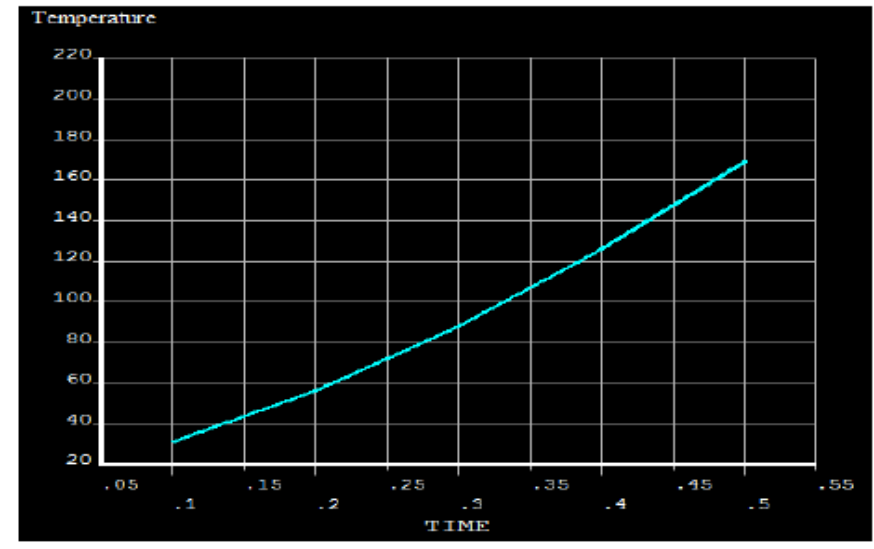

Fig 13 Temperature variation in the weld interface with each time step

\section{STRESS DISTRIBUTION IN THE MODEL}

Similar to the thermal analysis, the simulation was carried out for three different shape of the sonotrode and the resultsware presented in this ssection. The maximum Von Mises stress reached for the conical shape is $5.31 \square 10^{6} \mathrm{~N} / \mathrm{m}^{2}$ at the end of weld time. Fig. 4.11 shows distribution of stress for a conical shape sonotrode. It shows that the stress is maximum at the point of action of the clamping force, where the sonotrode meets with the top surface of the work piece and also in the bottom part where it touches the top surface of the anvil.

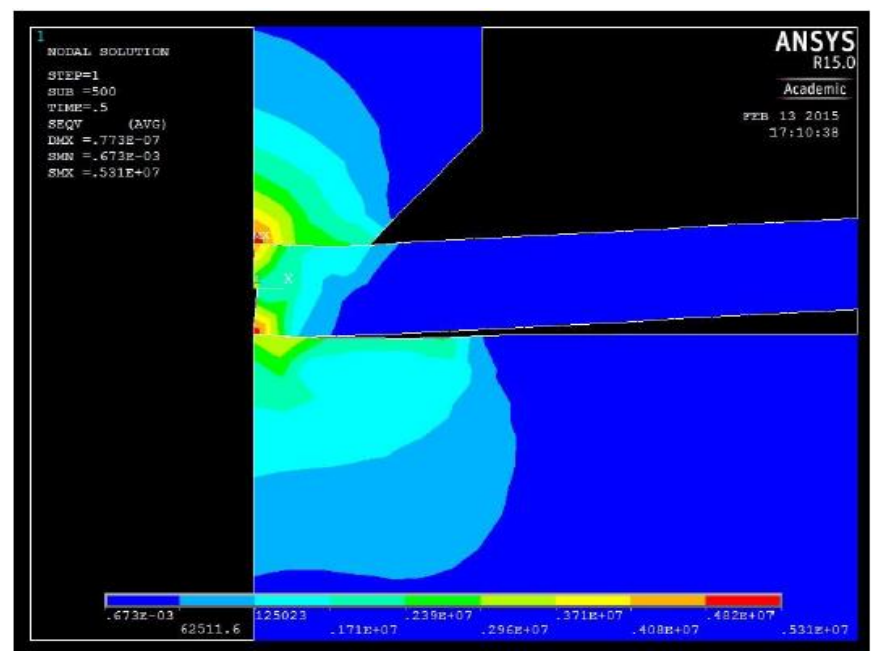

Fig 14. Stress distribution in model with conical shaped sonotrode

It can be seen, with the application of force the bottom work piece moves away from the anvil during welding. This could be because of improper clamping 
method adapted during welding. So a proper fixture needs to be design to hold the parts during welding. Fig. 13 shows the distribution of Von Mises stress in an exponential shaped sonotrode with a maximum of $5.8210^{6} \mathrm{~N} / \mathrm{m}^{2}$ at the end of the weld time.

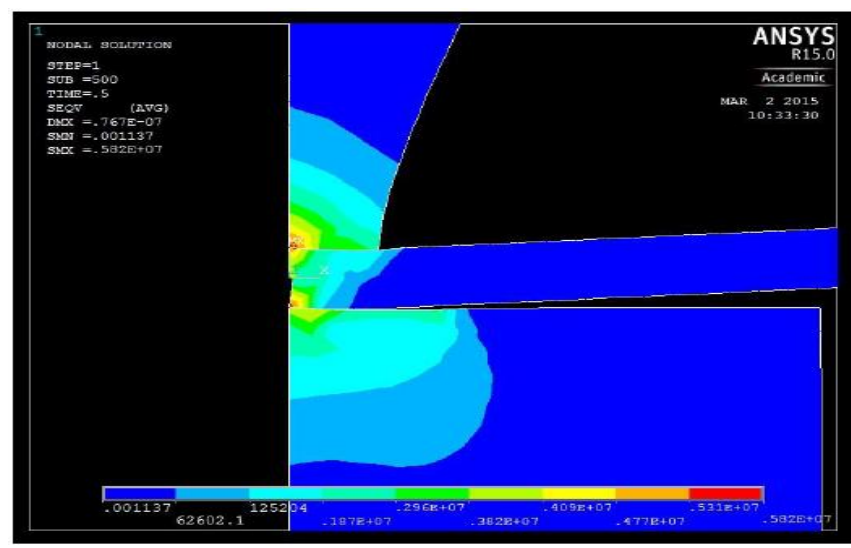

Fig 15. Stress distribution in model with exponential shaped sonotrode

Fig. shows the distribution of Von Mises stress in an exponential shaped sonotrode with a maximum of $6.2710^{6} \mathrm{~N} / \mathrm{m}^{2}$ at the end of the weld time. It can be seen from the figure that the Von Mises stress is more intense at the sonotrode because of the complexity of the model.

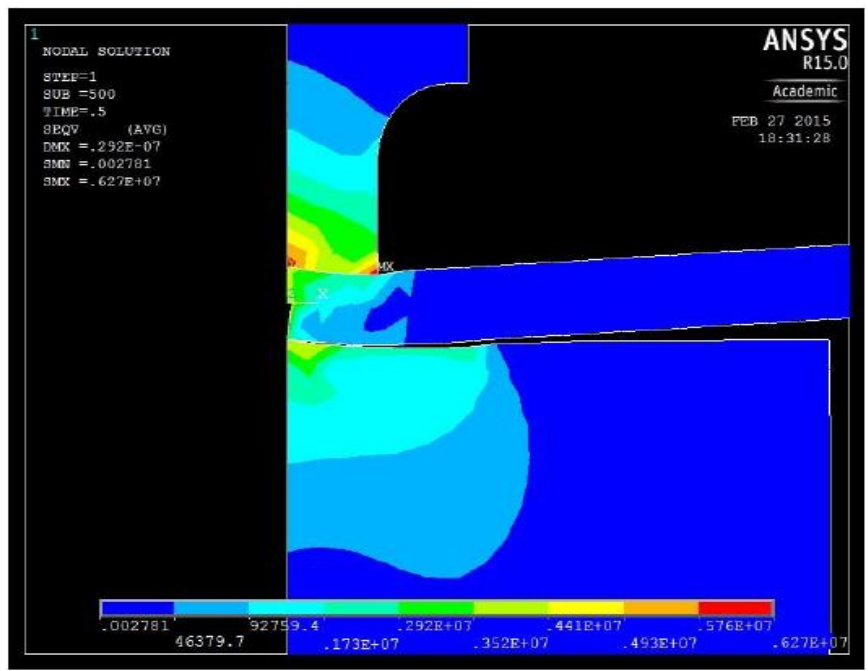

Fig 16. Stress distribution in model with exponential shaped sonotrode
Table 2. Temperature and stress distribution from the numerical model

\begin{tabular}{|l|l|l|}
\hline $\begin{array}{l}\text { Sonotrode } \\
\text { Shape }\end{array}$ & $\begin{array}{l}\text { Temperature in } \\
{ }^{\circ} \mathrm{C}\end{array}$ & $\begin{array}{l}\text { Von Mises } \\
\text { Stress in } \mathbf{N} / \mathbf{m}^{2}\end{array}$ \\
\hline Conical Shape & 169.238 & $\begin{array}{l}5.31 \\
\mathrm{x} 10^{6}\end{array}$ \\
\hline Exponential & 171.439 & 5.82 \\
Shape & & $\mathrm{x} 10^{6}$ \\
\hline Stepped Shape & 182.069 & 6.27 \\
& & $\times 10^{6}$ \\
\hline
\end{tabular}

\section{EXPERIMENTATION AND OPTIMIZATION TECHNIQUE}

\section{RESPONSE SURFACE METHODOLOGY}

It is a statistical tool used to establish a relationship between several controllable variables with one or more responses. The method was introduced by G.E.P. Box and K.B. Wilson. A series of experimental run are performed within the selected range to identify the best set of parameters which gives the optimum result for response variables. It assumes a second-degree polynomial consists of factors with coefficients for analysis. If the response variable linearly depends upon the factors, then it can be articulated by a first order polynomial but if there is any curvature in response surface then a second order model should be followed. A second order polynomial with $\mathrm{Z}$ as response variable is expressed by:

$Z= \pm a_{0} \pm a_{1} x \pm a_{2} y \pm a_{3} x^{2} \pm a_{4} y^{2} \pm a_{5} x y \pm e$

where:

$Z$ = response variable

$x, y=$ controllable factors

$e=$ experimental error

ao, $a_{1}, a_{2} \ldots=$ coefficients

In this work, from the vast literature survey three controllable factors such as pressure, amplitude, 
welding time at three levels were selected for conducting the experiment. A Box Behnken Design (BBD) is considered which gives a total of 17 experimental runs with 5 center points. Tensile strength of the welded joint is chosen as the response. The Factors and their levels are listed in Table 3

Table 3 Factors with levels

\begin{tabular}{|l|l|l|l|l|}
\hline Factor & Unit & & Levels & \\
\hline & & -1 & 0 & +1 \\
\hline Pressure & Bar & 1.4 & 1.6 & 1.8 \\
\hline $\begin{array}{l}\text { Amplitu } \\
\text { de }\end{array}$ & $\%$ & 21 & 24 & 27 \\
\hline $\begin{array}{l}\text { Weld } \\
\text { time }\end{array}$ & Sec & 0.4 & 0.45 & 0.5 \\
\hline
\end{tabular}

\section{EXPERIMENTAL PROCEDURE}

The experiments were performed on $3000 \mathrm{~W}, 20 \mathrm{KHz}$ ultrasonic welding machine on a $0.5 \mathrm{~mm}$ thickness Aluminum sheet, the experimental setup is shown in Fig. The pressure required for the welding is received from a compressor, where the maximum limit is set up to 18 bar prior to the welding. The holding time for the experiment is set as $0.3 \mathrm{sec}$. On the contact surface of the anvil and sonotrode knurl pattern were made to prevent sliding of the workpiece during welding. Fig. shows, specimens prepared for welding as per ASTM standards (D1002-01). Prior to the welding, the specimens were thoroughly cleaned with acetone to remove the surface impurities which can affect the joint strength. For each factorial combination, two trails of welded specimens were generated and the average of both the trials were also calculated and tabulated in Table 3 Fig. shows the ultrasonically welded specimens of $0.5 \mathrm{~mm}$ Aluminium sheet.

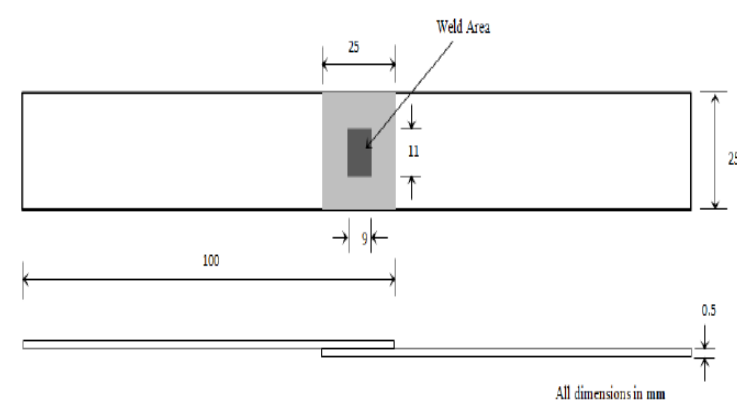

Fig 17. ASTM Standard (D1002-01) specimen

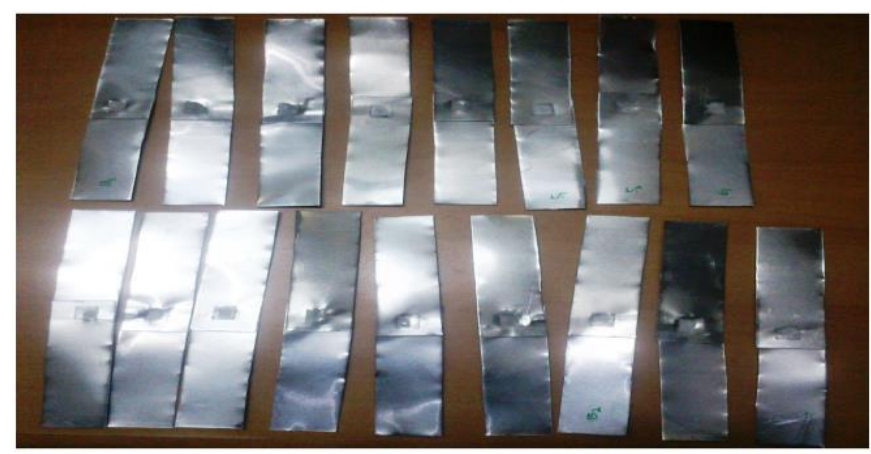

Fig 18. Ultrasonically welded specimens

Table 3. Experimental table

\begin{tabular}{|c|c|c|c|c|c|c|}
\hline \multirow{2}{*}{ Exp. no } & \multirow{2}{*}{ Pressure } & \multirow{2}{*}{ Amplitude } & \multirow{2}{*}{ Weld } & \multicolumn{3}{|c|}{ Tensile Strength } \\
\cline { 5 - 7 } & & & Time & Trial 1 & Trial 2 & Avg \\
\cline { 5 - 7 } & & & & & & \\
\hline 1 & 1.4 & 21 & 0.45 & 74.15 & 68.06 & 71.065 \\
\hline 2 & 1.8 & 21 & 0.45 & 90.01 & 84.38 & 87.045 \\
\hline 3 & 1.4 & 27 & 0.45 & 83.73 & 78.89 & 81.31 \\
\hline 4 & 1.8 & 27 & 0.45 & 83.38 & 81.97 & 82.675 \\
\hline 5 & 1.4 & 24 & 0.4 & 83.23 & 71.77 & 77.55 \\
\hline
\end{tabular}




\begin{tabular}{|c|c|c|c|c|c|c|}
6 & 1.8 & 24 & 0.4 & 86.39 & 92.58 & 89.375 \\
\hline 7 & 1.4 & 24 & 0.5 & 88.45 & 80.64 & 84.565 \\
\hline 8 & 1.8 & 24 & 0.5 & 92.74 & 94.17 & 93.21 \\
\hline 9 & 1.6 & 21 & 0.4 & 86.79 & 80.31 & 83.195 \\
\hline 10 & 1.6 & 27 & 0.4 & 74.73 & 86.55 & 80.64 \\
\hline 11 & 1.6 & 21 & 0.5 & 90.21 & 79.56 & 84.885 \\
\hline 12 & 1.6 & 27 & 0.5 & 85.19 & 79.74 & 82.465 \\
\hline 13 & 1.6 & 24 & 0.45 & 87.91 & 86.73 & 87.32 \\
\hline 14 & 1.6 & 24 & 0.45 & 87.82 & 81.4 & 84.61 \\
\hline 15 & 1.6 & 24 & 0.45 & 86.45 & 85.9 & 86.52 \\
\hline 16 & 1.6 & 24 & 0.45 & 87.21 & 80.93 & 84.52 \\
\hline 17 & 1.6 & 24 & 0.45 & 86.44 & 84.51 & 85.67 \\
\hline
\end{tabular}

The tensile strength of the joint is measured in a Computerized Tensile testing Machine with a constant cross head displacement of $5 \mathrm{~mm} / \mathrm{min}$. It was observed that, a ductile fracture occurs at the periphery of the weld except a few specimens which have poor weld quality. Some of the fractured specimens are shown in Fig.

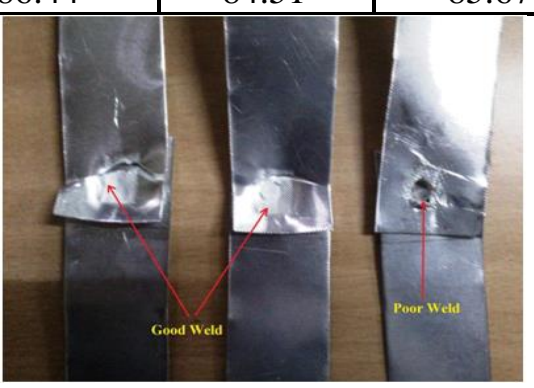

Fig 19. Fractured Specimens

Table 4 ANOVA for Tensile strength

\begin{tabular}{|c|c|c|c|c|c|c|}
\hline Source & Sum of & df & Mean & F Value & p-value & \\
\hline & Squares & & Square & & Prob > F & \\
\hline Model & 345.17 & 8 & 43.15 & 11.41 & 0.0012 & significant \\
\hline A-Pressure & 178.27 & 1 & 178.27 & 47.16 & 0.0001 & \\
\hline B- Amplitude & 0.33 & 1 & 0.33 & 0.075 & 0.7914 & \\
\hline C-weld time & 25.99 & 1 & 25.99 & 6.88 & 0.0306 & \\
\hline $\mathrm{A}^{*} \mathrm{~B}$ & 53.77 & 1 & 53.77 & 14.22 & 0.0055 & \\
\hline $\mathrm{B}^{*} \mathrm{C}$ & $9.025^{*} \mathrm{E}-3$ & 1 & $9.025^{*} \mathrm{E}-3$ & $2.089 * \mathrm{E}-3$ & 0.9648 & \\
\hline $\mathrm{A}^{*} \mathrm{C}$ & 2.53 & 1 & 2.53 & 0.67 & 0.4372 & \\
\hline $\mathrm{A}^{2}$ & 3.69 & 1 & 3.69 & 0.98 & 0.3519 & \\
\hline $\mathrm{B}^{2}$ & 72.49 & 1 & 72.49 & 19.17 & 0.0024 & \\
\hline $\mathrm{C} 2$ & 9.34 & 1 & 9.34 & 2.47 & 0.1546 & \\
\hline Residual & 30.24 & 8 & 3.78 & & & not \\
\hline Lack of Fit & 20.99 & 4 & 5.25 & 2.27 & 0.2236 & \\
\hline Pure Error & 9.26 & 4 & 2.31 & & & significant \\
\hline Core Total & 375.42 & 16 & & & & \\
\hline
\end{tabular}


Fig. shows the surface plot of tensile strength with pressure and amplitude. It illustrates that with the increase in pressure tensile strength increases as surface asperities come closer which helps the Vander Waal forces act better which leads to better bonding. With the increase in amplitude the strength also increases but after a certain level it slightly decreases as the heat energy is directly proportional to the square of the amplitude. The relation between amplitude and heat energy is given below:

$$
Q_{\text {avg }}=\frac{f \times \xi_{0}^{2} \times E^{\prime \prime}}{2}
$$

where:

$Q_{\text {avg }}=$ Heating rate

$f=$ frequency

$\xi_{0}=$ applied strain (proportional to amplitude)

$E=$ Complex loss modulus of the material

Hence, a little increase in amplitude causes a substantial increase in the heat and material in the deformation zone gets softer which sometimes leads to the joining of the parts with the anvil or sonotrode results in improper welding. Fig. 5.5 and Fig. 5.6 shows the surface plot of tensile strength with welding time and pressure and tensile strength with welding time and amplitude, it can be seen that with increase in welding time and pressure strength increases, this is because as weld time increase it gives sufficient time for scrubbing action and disrupt the contaminants results in better weld. The developed regression equation for maximizing tensile strength of the joint in terms of coded form is given as below:

Tensile strength $=+85.62+4.72 * \mathrm{~A}+2.2 * \mathrm{~B}+1.80^{*} \mathrm{C}-$ $3.67^{*} \mathrm{~A}^{*} \mathrm{~B}$

$-0.80^{*} \mathrm{~A}^{*} \mathrm{C}-0.94^{*} \mathrm{~A}^{2}-4.15^{*} \mathrm{~B}^{2}+1.49^{*} \mathrm{C}^{2}$

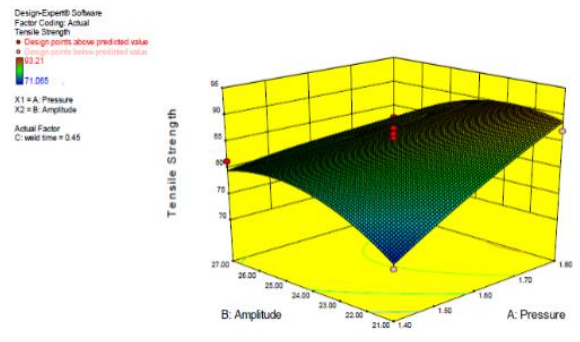

Fig 20. Surface plot of Tensile strength with Amplitude and Pressure
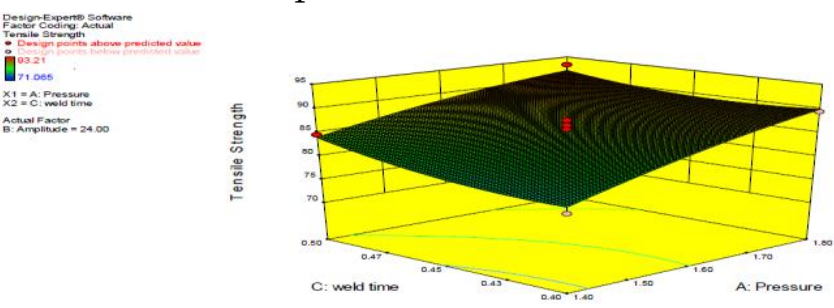

Fig 21. Surface plot of tensile strength with Weld time and Pressure

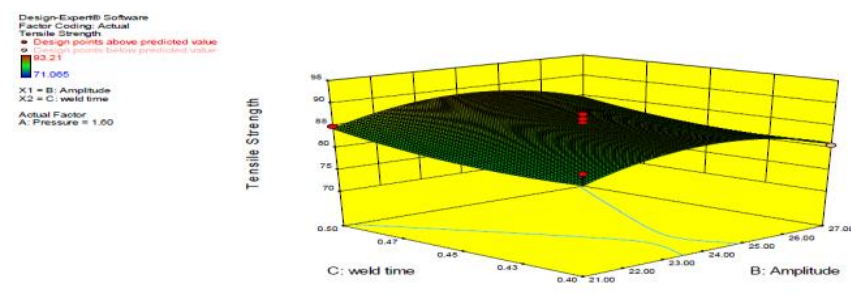

Fig 22. Surface plot of tensile strength with Weld time and Amplitude
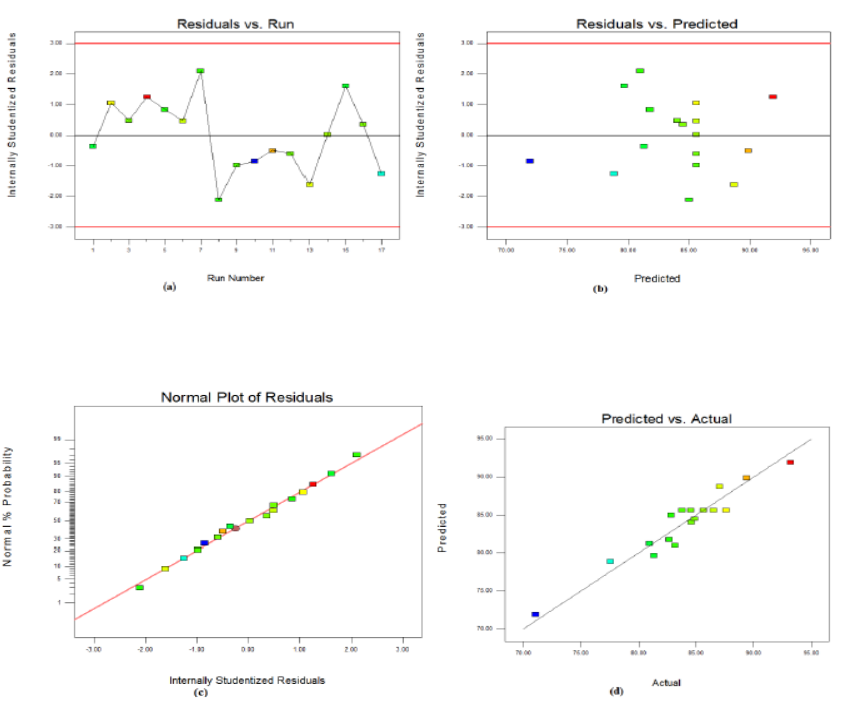

Fig 23. Residual plots for Tensile strengths (a) Residuals vs. Run, (b) Residuals vs. Predicted,Normal plot of residuals, (d) Predicted vs Actual 
Fig. shows the residual plots for tensile strength of the joint. The residuals versus experimental run plot indicate that the runs are evenly scattered around the mean line, this helps in checking for the hidden variables that may influence the response during welding. The residual versus predicted graph shows a random scattering of the values, it checks for constant variance. In the normal plot, the runs are arranged in a straight line which indicates that the residuals are following a normal distribution. The plot between predicted values versus actual value of responses indicates that the values are very close to each other and distributed near the man line.

\section{OPTIMIZATION USING DESIRABILITY FUNCTION}

The method was introduced by Derringer and Suich. In this method, the individual responses are altered into a corresponding desirability value and the range of desirability value varies between zero to one. When the value of the response is at its target value, which is the most desired place, then the desirability value is assigned to one. If the value of response is outside recommended tolerance range which is not desired, then its desirability value is assumed as zero. In this study higher-the-better criterion is chosen for the tensile strength of the joint. The individual desirability value for this criterion can be calculated by the formula given below:

$$
\begin{array}{rr}
\text { If } \hat{y} \leq y_{\min }, & d_{i}=0 \\
\text { If } y_{\min } \leq \hat{y} \leq y_{\max }, & d_{i}=\left(\frac{\hat{y}-y_{\min }}{y_{\max }-y_{\min }}\right)^{r} \\
\text { If } \hat{y} \geq y_{\max }, & d_{i}=1
\end{array}
$$

Here $y^{\wedge}$ represents the value of responses, $\min y$ represents the lower acceptable limit of $y^{\wedge}, \max y$ represents the upper acceptable limit of $y^{\wedge}$ and $r$ represents desirability function index, which needs to assign formerly as per the consideration of optimization solver. So when the equivalent response is estimated to be nearer to the target, then the function index is set to a higher value. In this study, $y_{\max }$ is taken as the highest observed value of the response $93.21 \mathrm{MPa}$ and $y_{\min }$ is taken as the lowest observed value of the response $71.065 \mathrm{MPa}$. The calculated value of process variables and the response is tabulated in Table 5.4 as per the descending order of the calculated desirability value. It was observed that the optimal parameter setting for tensile strength of the joint is pressure 1.8 bar, amplitude $22.75 \mu \mathrm{m}$, weld time $0.5 \mathrm{sec}$. The calculated value of tensile strength of the joint at optimal parameter setting is 92.6065 MPa having a desirability value of 0.973 .

Table 5 Desirability Table

\begin{tabular}{|c|c|c|c|c|c|}
\hline $\begin{array}{r}\text { Num } \\
\text { ber }\end{array}$ & Pressure & Amplitude & weld time & Tensile Strength & Desirability \\
\hline 1 & 1.80 & 22.75 & 0.50 & 92.6065 & 0.973 \\
\hline 2 & 1.80 & 22.80 & 0.50 & 92.6048 & 0.973 \\
\hline 3 & 1.80 & 22.70 & 0.50 & 92.6045 & 0.973 \\
\hline 4 & 1.80 & 22.73 & 0.50 & 92.5958 & 0.972 \\
\hline 5 & 1.80 & 22.77 & 0.50 & 92.5439 & 0.970 \\
\hline 6 & 1.80 & 23.13 & 0.50 & 92.51 & 0.968 \\
\hline 7 & 1.80 & 23.22 & 0.50 & 92.4876 & 0.967 \\
\hline
\end{tabular}




\begin{tabular}{|c|c|c|c|c|c|}
8 & 1.80 & 23.06 & 0.50 & 92.4789 & 0.967 \\
\hline 9 & 1.80 & 23.35 & 0.50 & 92.4511 & 0.966 \\
\hline 10 & 1.80 & 22.68 & 0.50 & 92.4221 & 0.964 \\
\hline 11 & 1.78 & 22.41 & 0.50 & 92.2718 & 0.958 \\
\hline 12 & 1.80 & 23.55 & 0.40 & 90.6312 & 0.884 \\
\hline 13 & 1.80 & 22.73 & 0.40 & 90.6306 & 0.884 \\
\hline 14 & 1.80 & 23.73 & 0.40 & 90.6252 & 0.883 \\
\hline 15 & 1.80 & 24.06 & 0.40 & 90.6217 & 0.883 \\
\hline 16 & 1.80 & 22.11 & 0.40 & 90.6074 & 0.882 \\
\hline 17 & 1.80 & 22.73 & 0.40 & 90.4968 & 0.877 \\
\hline 18 & 1.80 & 22.59 & 0.40 & 90.4172 & 0.874 \\
\hline 19 & 1.80 & 22.68 & 0.41 & 90.4079 & 0.873 \\
\hline 20 & 1.80 & 22.72 & 0.41 & 90.3949 & 0.873 \\
\hline 21 & 1.80 & 24.29 & 0.41 & 90.3081 & 0.869 \\
\hline 22 & 1.80 & 22.60 & 0.41 & 90.3073 & 0.869 \\
\hline 23 & 1.80 & 21.97 & 0.45 & 90.058 & 0.858 \\
\hline 24 & 1.80 & 22.69 & 0.42 & 90.0044 & 0.855 \\
\hline 25 & 1.80 & 22.75 & 0.43 & 89.9779 & 0.854 \\
\hline & & & & & \\
\hline
\end{tabular}

Fig. 24 shows the surface plot for desirability with amplitude and pressure, it can be seen that the maximum desirability value reached at pressure of 1.8 bar and amplitude of $22.75 \mu \mathrm{m}$.
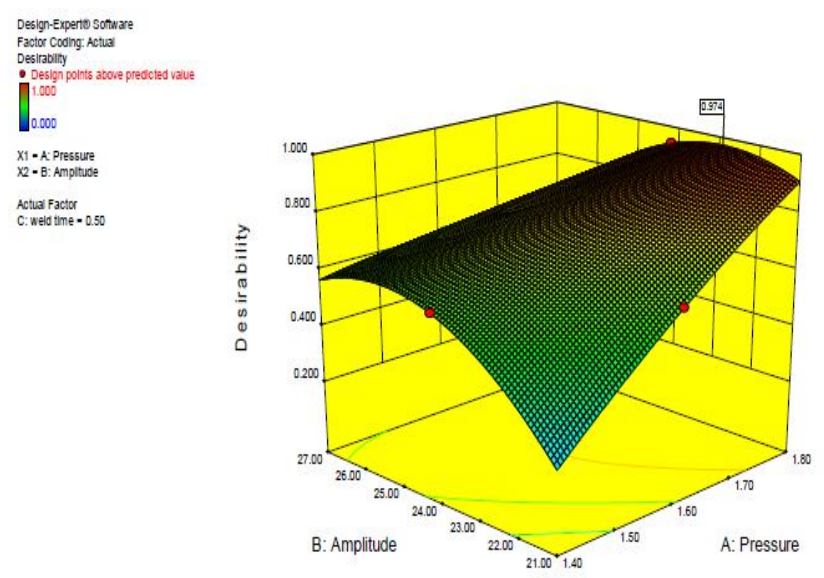

Fig 24. Surface plot for Desirability with Amplitude and Pressure

\section{VALIDATING THE FE MODEL FOR TEMPERATURE DISTRIBUTION}

The temperature at the weld interface is measured during welding with the help of a data acquisition system. The data acquisition system consists of a Ktype thermocouple (sensor), a DAQ card, a computer with analyzing software. The thermocouple is capable of measuring a temperature range from $-180{ }^{\circ} \mathrm{C}$ to $+1260{ }^{\circ} \mathrm{C}$. Fig. shows, the set up for ultrasonic metal welding with temperature measurement attachment.

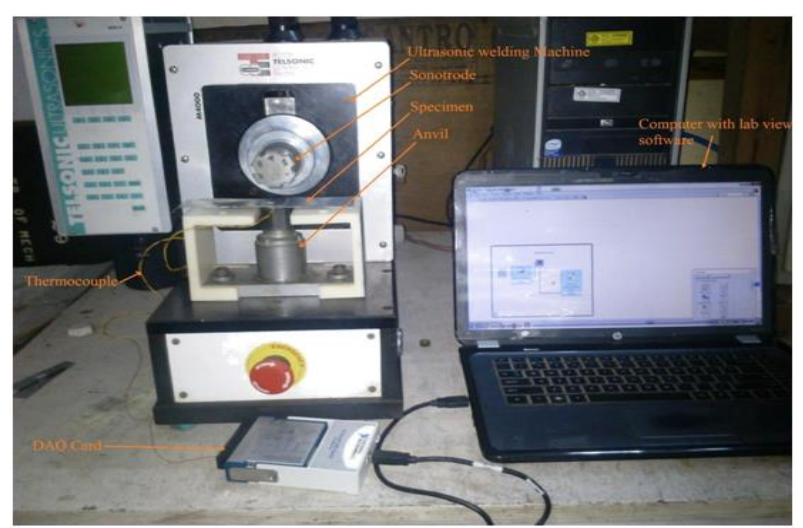

Fig 25. Experimental set up with temperature measurement attachment

The experiments were conducted at the optimum parameter setting which is evaluated in next chapter. The parameters were set as pressure of 1.8 bar, amplitude at $80 \%(37.08 \mu)$, and weld time at $0.5 \mathrm{sec}$. 
The experiment at same level of parameter is repeated for 3 times and the maximum value of temperature observed is $176.223{ }^{\circ} \mathrm{C}$ with comparing to the model result of maximum temperature $182.069{ }^{\circ} \mathrm{C}$ which was generated in stepped sonotrode shape, a relative error of
$3.32 \%$ observed. The data gathered from the software is listed in Table 5.5. A graph is plotted for temperature against time in Fig.

Table 6. Temperature readings with time from lab view software

\begin{tabular}{|c|c|c|c|}
\hline Si. No. & & Temperature $\left({ }^{0} \mathrm{C}\right)$ & \\
\hline & Trial 1 & Trial 2 & Trial 3 \\
\hline 1 & 29.759544 & 29.309207 & 30.524261 \\
\hline 2 & 30.517624 & 29.333454 & 30.495402 \\
\hline 3 & 30.358214 & 29.356395 & 30.470985 \\
\hline 4 & 30.857415 & 39.738548 & 30.413762 \\
\hline 5 & 176.22367 & 154.31596 & 174.81667 \\
\hline 6 & 145.17256 & 123.44487 & 147.25466 \\
\hline 7 & 91.280436 & 98.276223 & 97.756236 \\
\hline 8 & 83.521031 & 81.943958 & 85.685131 \\
\hline 9 & 77.393324 & 63.612485 & 76.798424 \\
\hline 10 & 73.239116 & 55.117937 & 71.836616 \\
\hline 11 & 68.400442 & 47.973039 & 68.592462 \\
\hline 12 & 65.860792 & 42.293895 & 62.860792 \\
\hline 13 & 63.071146 & 39.059449 & 61.071146 \\
\hline 14 & 60.522932 & 36.584705 & 57.522932 \\
\hline 15 & 57.650652 & 36.215455 & 55.650652 \\
\hline 16 & 55.130103 & 34.882099 & 53.130503 \\
\hline 17 & 53.395178 & 33.268054 & 51.395178 \\
\hline 18 & 51.252142 & 32.494824 & 50.394752 \\
\hline 19 & 49.475485 & 31.692761 & 49.632425 \\
\hline 20 & 46.258419 & 31.293433 & 47.788949 \\
\hline 21 & 45.413527 & 30.882567 & 46.279405 \\
\hline 22 & 44.125496 & 30.563878 & 45.294345 \\
\hline 23 & 43.985753 & 30.403711 & 44.297961 \\
\hline 24 & 42.751466 & 31.801993 & 43.047485 \\
\hline 25 & 41.445751 & 34.032967 & 42.070274 \\
\hline 26 & 40.236554 & 32.636755 & 41.227193 \\
\hline 27 & 40.449971 & 32.418425 & 40.449971 \\
\hline
\end{tabular}




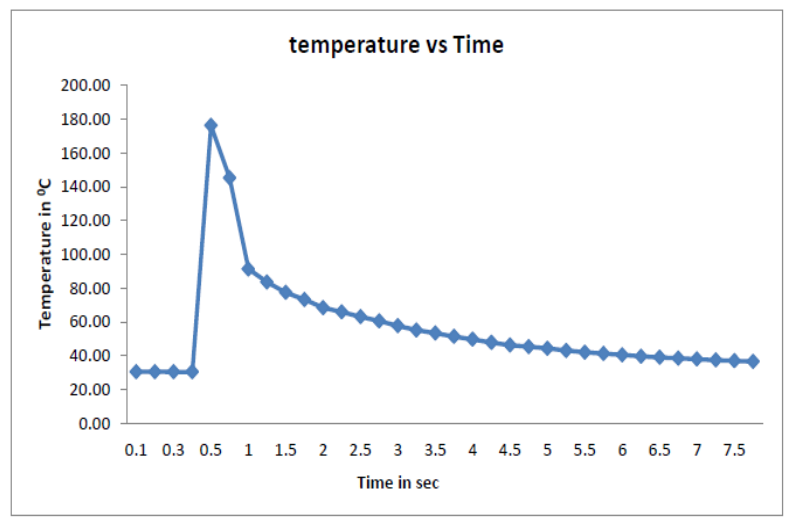

Fig 26. Observed temperature variation with time

\section{VI.CONCLUSION}

\section{SUMMARY OF THE FINDINGS}

After carrying out a systematic study the following extrapolation can be summarized:

1. An FEM based analysis is done for ultrasonic welding by taking Aluminium as workpiece material and mild steel as sonotrode and anvil material. The model can predict the temperature and stress distribution with different shape of the sonotrode.

2. It can be also understood from the study that the temperature distribution at the work piece is more as compared to the sonotrode and anvil as the thermal conductivity of Aluminum is more as compared to steel and thermal load is applied at the center of the weld.

3. If we compare between different sonotrode shapes then we can see that the temperature generated by stepped shape $182.069^{\circ} \mathrm{C}$ is maximum as compared to exponential and stepped shape. Similarly, stress generated due to clamping force for the stepped shape $0.627 \times 10^{7}$ $\mathrm{N} / \mathrm{m}^{2}$ is maximum.

4. The proposed RSM model gives the importance of the process variables such as pressure, amplitude, and weld time on the tensile strength of the joint.
5. From the desirability function the optimum parameter setting is obtained as pressure $1.8 \mathrm{bar}$, amplitude $22.75 \mu \mathrm{m}$, weld time $0.5 \mathrm{sec}$ with a desirability value of 0.974 .

6. The temperature generation from the FE model is validated by conducting experiment and found out as $176.22{ }^{\circ} \mathrm{C}$, with a relative error of $3.32 \%$.

7. The research work offers an effective guideline to select optimum parameter settings for achieving desired tensile strength.

\section{RECOMMENDATION AND FUTURE SCOPE}

From the current work it was found out that the conical shape generates minimum value of temperature and stress, so the shape of the tool is recommended when a welding required for soft and thin material. Whereas stepped shape sonotrode is recommended for relatively thick material. For the joining of $0.5 \mathrm{~mm}$ Aluminium foil in $3000 \mathrm{~W}$ machine, it is recommended that the value of amplitude should be less than $22 \mu \mathrm{m}$.

The present research work is carried out for Aluminium as workpiece material and mild steel as sonotrode and anvil material. Still there is a vast area to explore for this novel welding process. Hence, future work can carried out in the following direction:

1. Ultrasonic welding of dissimilar materials with suitable experimental design and parameter setting.

2. Effect of shape of the anvil on the welding process.

\section{REFERENCES}

[1]. Elangovan, S., Semeer, S., and Prakasan, K. (2009). Temperature and stress distribution in ultrasonic metal welding-An FEA-based 
study. Journal of materials processing technology, 209(3), 1143-1150.

[2]. Siddiq, A., and Ghassemieh, E. (2008). Thermomechanical analyses of ultrasonic welding process using thermal and acoustic softening effects. Mechanics of Materials, 40(12), 982-1000.

[3]. Konchakova, N., Balle, F., Barth, F. J., Mueller, R., Eifler, D., and Steinmann, P. (2010). Finite element analysis of an inelastic interface in ultrasonic welded metal/fibre-reinforced polymer joints. Computational Materials Science, 50(1), 184-190.

[4]. Levy, A., Le Corre, S., Chevaugeon, N., and Poitou, A. (2011). A level set based approach for the finite element simulation of a forming process involving multiphysics coupling: Ultrasonic welding of thermoplastic composites. European Journal of MechanicsA/Solids, 30(4), 501-509.

[5]. De Vries, E. (2004). Mechanics and mechanisms of ultrasonic metal welding(Doctoral dissertation, The Ohio State University).

[6]. Amin, S. G., Ahmed, M. H. M., and Youssef, H. A. (1995). Computer-aided design of acoustic horns for ultrasonic machining using finiteelement analysis. Journal of Materials Processing Technology, 55(3), 254-260.

[7]. Pandya Bhavik, Patel Saral, and Patel Viral (2014). Effect of horn (sonotrode) profile on weld strength of HDPE plastic by using ultrasonic welding. International Journal for Technological Research and Engineering, 2(4), 2347-4718

[8]. Zhang, C. Q., Robson, J. D., Ciuca, O., and Prangnell, P. B. (2014). Microstructural characterization and mechanical properties of high power ultrasonic spot welded aluminum alloy AA6111-TiA16V4 dissimilar joints. Materials Characterization, 97, 83-91.
[9]. Villegas, I. F. (2014). Strength development versus process data in ultrasonic welding of thermoplastic composites with flat energy directors and its application to the definition of optimum processing parameters. Composites Part A: Applied Science and Manufacturing, 65, 27-37.

[10]. Panteli, A., Chen, Y. C., Strong, D., Zhang, X., and Prangnell, P. B. (2012). Optimization of aluminium-to-magnesium ultrasonic spot welding. Journal of Minerals, Metals and materials, 64(3), 414-420.

[11]. Sooriyamoorthy, E., Henry, S. P. J., and Kalakkath, P. (2011). Experimental studies on optimization of process parameters and finite element analysis of temperature and stress distribution on joining of $\mathrm{Al}-\mathrm{Al}$ and $\mathrm{Al}-\mathrm{Al} 2 \mathrm{O} 3$ using ultrasonic welding. The International Journal of Advanced Manufacturing Technology, 55(5-8), 631-640.

[12]. Liu, S. J., Lin, W. F., Chang, B. C., Wu, G. M., and Hung, S. W. (1999). Optimizing the joint strength of ultrasonically welded thermoplastics. Advances in Polymer Technology, 18(2), 125-135.

[13]. Wijk, H., Luiten, G. A., Engen, P. G., and Nonhof, C. J. (1996). Process optimization of ultrasonic welding. Polymer Engineering and Science, 36(9), 1165-1176.

[14]. Elangovan, S., Venkateshwaran, S., and Prakasan, K. (2012). Experimental Investigations on Optimization of Ultrasonic Welding Parameters for Copper to Brass Joints Using Response Surface Method and Genetic Algorithm. International Journal of Advanced Engineering Research and Studies, 1(3), 1-6..

[15]. Harras, B., Cole, K. C., and Vu-Khanh, T. (1996). Optimization of the ultrasonic welding of PEEK-carbon composites. Journal of 
reinforced plastics and composites, 15(2), 174182.

[16]. Kim, T. H., Yum, J., Hu, S. J., Spicer, J. P., and Abell, J. A. (2011). Process robustness of single lap ultrasonic welding of thin, dissimilar materials. CIRP Annals-Manufacturing Technology, 60(1), 17-20.

[17]. ASTM International Codes, "Standard Test Method for Apparent Shear Strength of SingleLap-Joint Adhesively Bonded Metal Specimens by Tension Loading (Metal-to-Metal)," ASTM International, Vol.01, 2005, pp. 52-55.

\section{Cite this article as :}

Sh 